\title{
A MICROCOMPUTER BASED PARK RESOURCES MANAGEMENT SYSTEM FOR GLACIER NATIIONAL PARK
}

\author{
Michael J. Magee \\ Computer Science Department \\ University of Wyoming
}

\section{Objectives}

The primary objective of this project is to assess the computing needs of the Glacier National Park and to make recommendations with respect to the management of park resources. As originally proposed, one of the principal objectives was to consult with the park service and to suggest alternatives for hardware configurations that would meet the ever increasing information management requirements of Glacier National Park. Before the initial meeting between the principal investigator and park service personnel, however, a Datapoint minicomputer was selected by the regional office in Denver for use by Glacier as well as other parks within the area. Thus, the objectives to be attained by this and subsequent reports will deal primarily with the uses to which the newly acquired hardware can be put as well as suggesting methods of operation and additional hardware which would enhance information processing at Glacier National Park.

\section{Procedure}

Discussions were held with numerous members of the Glacier National Park stafi during August, 1981. These discussions took the form of question/ answer sessions at which park service personnel described their special inrormation processing needs and inquired as to the feasibility of performing such processing on the newly acquired equipment. It was apparent that the computing needs of Glacier National Park in general go beyond the capabilities of the new equipment as it will be initially configured, but that special hardware may be added to better serve these needs.

\section{Preliminary Recommendations}

It is obvious to the investigator that all of the varied needs of Glacier National Park cannot be met by the initially configured Datapoint system. There are several needs that are immediately satisfiable, however. First, the research unit (as well as other units at Glacier) have a considerable volume of document preparation such as technical and status reports. The amount of computational power needed for text processing is minimal and the amount of computer expertise to use such 
processors is likewise smal1. Typically, such document preparation is done by secretaries with little or no programming experience. Use of the Datapoint for this application would be of immediate benefit to virtually all units within the park service since editing of documents is facilitated. Furthermore, if the basic form and/or information in documents submitted on a periodic basis has only minor changes, these documents can be archived (stored on a removable disk), updated as needed, and hardcopied for the current report. The overhead secretarial time needed for document preparation is reduced because of the capabilities of the text processor itself.

A second immediate use of the Datapoint system is in the area of park resource inventories and wildlife management. This is a more difficult application to address since the volume of information varies widely, and in some cases would be too large to be accommodated on the initially configured system. As a sample case, however, consider the information gathered on bear sightings. Daily bear sightings that are reported to the research unit are noted (by hand) on a large map of the park. While it is easy to visually inspect this map for trends in sightings of bears, it is not as easy to gather statistics on bear populations, or to diagnose trends over a period of years. If this information were available on removable disks, with an appropriate date query/update language then the research usage of the machine would be considerably enhanced. Automatic mapping of sightings could also be accomplished with the addition of a graphics terminal.

Special areas of investigation such as fire management are also feasible using computer modelling. The correlation of fire danger indices with actual fire histories, for example, would be possible if the data were archived for computer usage. Park personnel wanting to know answers to fire histories (e.g. how many class B fires were between 1971 and 1979) would be aided by the query/update capability.

Other needs of Glacier National Park that can be addressed by an augmented system (large fast disk) include issuing of backcountry use permits, visitor statistics, vehicle maintenance statistics, and payroll computations.

\section{Current Directions for Further Investigation}

The PI is currently supervising a graduate assistant for the purpose of developing a prototype data base query/update language for resource management within Glacier National Park. It is the intent of this prototype software to demonstrate how the park service may use such a language to facilitate storage and examination of various types of data that it records. 